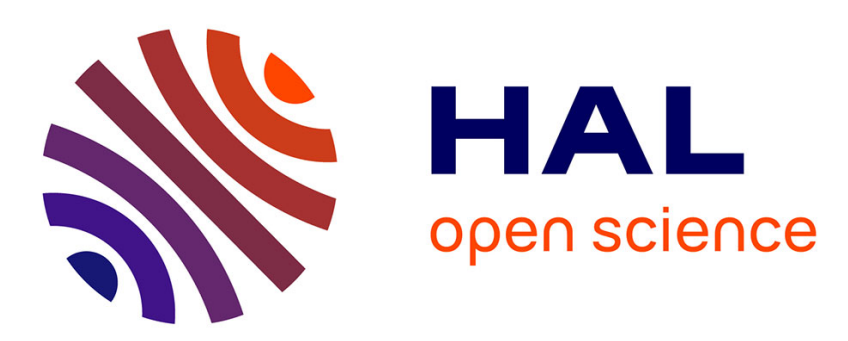

\title{
The DGAT2 gene is a candidate for dissociation between fatty liver and insulin resistance in humans
}

Konstantinos Kantartzis, Fausto Machicao, Jürgen Machann, Fritz Schick, Andreas Fritsche, Hans-Ulrich Häring, Norbert Stefan

\section{- To cite this version:}

Konstantinos Kantartzis, Fausto Machicao, Jürgen Machann, Fritz Schick, Andreas Fritsche, et al.. The DGAT2 gene is a candidate for dissociation between fatty liver and insulin resistance in humans. Clinical Science, 2009, 116 (6), pp.531-537. 10.1042/CS20080306 . hal-00479444

\section{HAL Id: hal-00479444 https://hal.science/hal-00479444}

Submitted on 30 Apr 2010

HAL is a multi-disciplinary open access archive for the deposit and dissemination of scientific research documents, whether they are published or not. The documents may come from teaching and research institutions in France or abroad, or from public or private research centers.
L'archive ouverte pluridisciplinaire HAL, est destinée au dépôt et à la diffusion de documents scientifiques de niveau recherche, publiés ou non, émanant des établissements d'enseignement et de recherche français ou étrangers, des laboratoires publics ou privés. 


\section{The DGAT2 Gene is a Candidate for Dissociation between Fatty Liver}

\section{and Insulin Resistance in Humans}

Konstantinos Kantartzis ${ }^{1}$, Fausto Machicao ${ }^{1}$, Jürgen Machann ${ }^{2}$, Fritz Schick ${ }^{2}$, Andreas Fritsche ${ }^{1}$, HansUlrich Häring $^{1}$, Norbert Stefan ${ }^{1}$

Short title: DGAT2, Insulin Resistance and Fatty Liver

${ }^{1}$ Department of Internal Medicine, Division of Endocrinology, Diabetology, Vascular Medicine, Nephrology and Clinical Chemistry, University of Tübingen, Germany

${ }^{2}$ Section on Experimental Radiology, University of Tübingen, Germany

Address for correspondence:

Norbert Stefan, MD

Department of Internal Medicine

Otfried-Müller-Str. 10,

72076 Tübingen, Germany

phone: +49-7071-2980390,

fax: +49-7071-295974

email: norbert.stefan@med.uni-tuebingen.de

Keywords: Diabetes, fatty liver, DGAT, insulin resistance, lifestyle intervention, obesity 


\section{Abstract}

The enzyme acyl-CoA:diacylglycerol acyltransferase (DGAT) catalyzes the final step of triglyceride synthesis. Mice overexpressing hepatic DGAT2, fed a high-fat diet, develop fatty liver, but not insulin resistance, suggesting that DGAT2 induces dissociation between fatty liver and insulin resistance. We investigated whether such a phenotype also exists in humans. For this purpose, we determined the relationships of genetic variability in the DGAT2 gene with changes in liver fat and in insulin sensitivity in 187 extensively phenotyped subjects during a lifestyle intervention with diet modification and increase in physical activity. Changes in body fat composition [magnetic resonance (MR) tomography], liver fat and intramyocellular fat $\left({ }^{1} \mathrm{H}-\mathrm{MR}\right.$ spectroscopy) and insulin sensitivity (OGTT and euglycemic, hyperinsulinemic clamp) were determined after 9 months of intervention.

Change in insulin sensitivity correlated inversely with changes in total body fat, visceral fat intramyocellular fat and liver fat (OGTT: all $\mathrm{p}<0.05$; clamp: all $\mathrm{p} \leq 0.03$ ). Changes in total body fat, visceral fat and intramyocellular fat were not different between the genotypes of the single nucleotide polymorphisms (SNP) rs10899116 C > T and rs $1944438 \mathrm{C}>\mathrm{T}$ (all $\mathrm{p} \geq 0.39$ ). However, individuals carrying two or one copies of the minor T allele of SNP rs 1944438 had less decrease in liver fat (-17 \pm 10 and $-24 \pm 5 \%$, mean \pm standard error) compared to subjects homozygous for the $\mathrm{C}$ allele $(-39 \pm 7 \%, \mathrm{p}=0.008)$. In contrast, changes in insulin sensitivity were not different among the genotypes (OGTT: $\mathrm{p}=0.76$; clamp: $\mathrm{p}=0.53$ ).

Our findings suggest that DGAT2 mediates dissociation between fatty liver and insulin resistance in humans. This finding may be important in the prevention and treatment of insulin resistance and type 2 diabetes in subjects with fatty liver. 


\section{Introduction}

Nonalcoholic fatty liver disease represents a strong predictor of insulin resistance, the metabolic syndrome, cardiovascular disease and type 2 diabetes [1-5]. However, despite the strong association of fatty liver with insulin resistance [6-8], subjects can be identified who, for the same amount of liver fat, have very high and low insulin resistance. When accumulation of liver fat is not accompanied by respective increase in insulin resistance, the term "dissociation" is used [9;10] Recent animal data suggest that a possible explanation for this dissociation between fat accumulation in the liver and insulin resistance may be variation in the expression and/or activity of the enzyme acyl-CoA: diacylglycerol acyltransferase (DGAT). This enzyme catalyzes the final step of triglyceride synthesis [11;12]. There are two isoforms of the enzyme, DGAT1 and DGAT2. DGAT2 is specific for triglyceride synthesis and is predominantly expressed in the liver [11]. Mice overexpressing DGAT2 develop fatty liver but, unexpectedly, not insulin resistance under a high-fat diet [9]. In agreement, treatment with antisense oligonucleotide causing a reduction in the expression of DGAT2 gene (DGAT2) resulted in an improvement of hepatic steatosis without change in insulin sensitivity [13]. In another study with similar design in rats insulin sensitivity improved as well, but this may have been due to the observed reduction in body weight [14].

With the present study we set out to delineate whether DGAT2 plays a role in the dissociation of fatty liver and insulin resistance in humans. We studied the relationships of common single nucleotide polymorphisms (SNPs) in DGAT2 with liver fat and insulin sensitivity during a lifestyle intervention. Precise phenotyping methods as magnetic resonance tomography (MRT) to measure total body fat and fat content in the visceral as well as in the subcutaneous depots and ${ }^{1} \mathrm{HMR}$ spectroscopy to determine fat deposition in ectopic tissues as liver and skeletal muscle were used. 


\section{Methods}

\section{Subjects}

Data of 187 Caucasians, 72 men and 115 women, without type 2 diabetes from the southern part of Germany were analyzed. These individuals participated in an ongoing study to reduce adiposity and prevent type 2 diabetes [15;16]. Individuals were included in the study when they fulfilled at least one of the following criteria: a family history of type 2 diabetes, a BMI $>27 \mathrm{~kg} / \mathrm{m}^{2}$, a previous diagnosis of impaired glucose tolerance and/or of gestational diabetes. They were considered healthy according to a physical examination and routine laboratory tests. Subjects had no history of liver disease and did not consume more than 2 alcoholic drinks per day. They had measurements at baseline and after a mean of 9 months of lifestyle intervention. After the baseline measurements, individuals underwent dietary counseling and had up to ten sessions with a dietician. During each visit participants presented a 3-day food diary and discussed the results with the dieticians. Diet composition was determined with a validated computer program using 2 representative days of a 3 -day diary (DGE-PC $3 \cdot 0$, Deutsche Gesellschaft für Ernährung, Bonn, Germany). Counseling was aimed to reduce body weight by $\geq 5 \%$, to reduce the intake of calories from fat to $<30 \%$ and particularly the intake of saturated fat to $\leq 10 \%$ of energy consumed and to increase the intake of fibers to at least $15 \mathrm{~g} / 1000 \mathrm{kcal}$. Individuals were asked to perform at least 3 hours of moderate sports per week. Aerobic endurance exercise (e.g. walking, swimming) with an only moderate increase in the heart rate was encouraged. Participants were seen by the staff on a regular basis to ensure that these recommendations were accomplished. The research has been carried out in accordance with the Declaration of Helsinki (2000) of the World Medical Association. Informed written consent was obtained from all participants and the local medical ethics committee approved the protocols. 


\section{Body fat distribution, liver fat and intramyocellular fat}

Waist circumference was measured at the midpoint between the lateral iliac crest and lowest rib. Total body- and visceral fat were measured by MR tomography, and liver fat and intramyocellular fat of the tibialis anterior muscle by ${ }^{1} \mathrm{H}-\mathrm{MR}$ spectroscopy as previously described [17].

\section{Oral glucose tolerance test}

All individuals underwent a $75 \mathrm{~g}$ oral glucose tolerance test (OGTT). We obtained venous plasma samples at 0, 30, 60, 90 and 120 minutes for determination of plasma glucose and insulin. Glucose tolerance was determined according to the 1997 World Health Organization diagnostic criteria [18]. Insulin sensitivity from the OGTT was calculated as proposed by Matsuda and DeFronzo (10 000 / $\sqrt{ }($ mean insulin $\mathrm{x}$ mean glucose) $\mathrm{x}$ (fasting insulin $\mathrm{x}$ fasting glucose) [19].

\section{Euglycemic, hyperinsulinemic clamp}

A subgroup ( $\mathrm{n}=142$ at baseline and $\mathrm{n}=46$ at follow-up) additionally underwent a euglycemic, hyperinsulinemic clamp. Insulin sensitivity was determined with a primed insulin infusion at a rate of $40 \mathrm{mU} \cdot \mathrm{m}^{-2} \cdot \mathrm{min}^{-1}$ for 2 hours as previously described [17]. In these subgroups of individuals, insulin sensitivity calculated from the OGTT was strongly correlated with insulin sensitivity measured during the clamp ( $\mathrm{r}=0.72, \mathrm{p}<0.0001$ at baseline and $\mathrm{r}=0.78, \mathrm{p}<0.0001$ at follow-up).

\section{Genotyping}

SNPs that are representative in a region of the genome with high linkage disequilibrium (the nonrandom association of alleles at two or more loci - tagging SNPs) allow identifying genetic variation without genotyping every SNP in a chromosomal region. Tagging SNPs for DGAT2 were selected from 
HapMap (HapMap Public Release no. 22). Applying a pairwise tagging SNP $\mathrm{r}^{2}$ threshold of 0.8, 2 SNPs (rs10899116 and rs1944438) had a minor allele frequency (MAF) $\geq 0.05$ and covered $100 \%$ of the alleles with a D' of 1 (Haploview Program). Thus, these two SNPs are representative for all SNPs in DGAT2 which have a relevant frequency in the general population. These SNPs were genotyped in our population by direct sequencing and using the TaqMan assay (Applied Biosystems, Foster City,CA, USA).

\section{Statistical analyses}

For statistical analyses, non-normally distributed parameters were logarithmically transformed.

Relationships between parameters at baseline and at follow-up were tested using the paired t-test. To test the effect of genotype on the metabolically relevant parameters, multivariate linear regression models were used with the parameter to be considered set as the dependent variable. In cross-sectional analyses differences in parameters at baseline between genotypes were tested. Body weight, waist circumference and total body fat were adjusted for age and gender. The other parameters were additionally adjusted for total body fat. In longitudinal analyses, changes in parameters during the intervention between genotypes were tested. Change in body weight, waist circumference and total body fat were adjusted for the respective baseline values, gender and age at follow-up. Changes in the other parameters were additionally adjusted for body fat at baseline and follow-up. The genotype was included in both analyses as an independent nominal variable. For each dependent variable two models were applied. In the additive model the effects of all possible genotypes on the dependent variable were compared; in the dominant model homozygotes for the major allele were compared to heterozygotes and homozygotes of the minor allele. A p-value $\leq 0.05$ was considered statistically significant. The statistical software package JMP 4.0 (SAS Institute Inc, Cary, NC, USA) was used. 


\section{Results}

\section{Cross-sectional analyses}

The anthropometrics and metabolic characteristics of the subjects at baseline are shown in table 1. All parameters at baseline covered a wide range. Seventy-one subjects (38\%) were obese (BMI > 30 $\mathrm{kg} / \mathrm{m}^{2}$ ) and $49(26.2 \%)$ had impaired glucose tolerance (IGT) at baseline. According to the cut-off of liver fat 5.56\% [20], 54 individuals were found to have fatty liver at baseline. Liver fat was higher in males than females (median [interquartile range]; 4.28 [2.48-11.19] vs. 2.26 $[1,17-4.46] \%, \mathrm{p}<0.0001)$ and correlated significantly with age $(\mathrm{r}=0.15, \mathrm{p}=0.04)$, total body fat $(\mathrm{r}=0.28$, $\mathrm{p}=0.0001)$, visceral fat $(\mathrm{r}=0.62, \mathrm{p}<0.0001)$, intramyocellular fat $(\mathrm{r}=0.18, \mathrm{p}=0.02)$, and inversely with insulin sensitivity (OGTT, $\mathrm{r}=-0.54, \mathrm{p}<0.0001$, clamp, $\mathrm{r}=-0.58, \mathrm{p}<0.0001$ ).

Insulin sensitivity was higher in females (OGTT, 12.97 [8.47-18.04] vs. 9.37 [6.81-14.12] arb. units, $\mathrm{p}=0.02$; clamp, 0.066 [0.047-0.090] vs. $\left.0.054[0.037-0.071] \mu \mathrm{mol} \cdot \mathrm{kg}^{-1} \cdot \mathrm{min}^{-1} \cdot \mathrm{pM}^{-1}, \mathrm{p}=0.009\right)$ and correlated with total body fat (OGTT, $r=-0.39, \mathrm{p}<0.0001$; clamp, $\mathrm{r}=-0.39, \mathrm{p}<0.0001$ ), visceral fat (OGTT, $\mathrm{r}=-0.47, \mathrm{p}<0.0001$; clamp, $\mathrm{r}=-0.51, \mathrm{p}<0.0001)$ and intramyocellular fat (OGTT, $\mathrm{r}=-0.28$, $\mathrm{p}=0.0004$; clamp, $\mathrm{r}=-0.27, \mathrm{p}=0.002$ ).

Both SNPs, rs 10899116 and rs 1944438 , were in Hardy-Weinberg equilibrium ( $\chi^{2}$-test; $p \geq 0.75$ ). The minor allele frequency (MAF) of the SNPs rs $10899116 \mathrm{C}>\mathrm{T}$ and $\mathrm{rs} 1944438 \mathrm{C}>\mathrm{T}$ were 0.09 and 0.39 , respectively. The SNP rs 10899116 was not associated with anthropometrics or metabolic characteristics. In a dominant model the SNP rs 1944438 was not associated with age or gender. No relationship of this SNP with insulin sensitivity, visceral-, liver- or intramyocellular fat, all adjusted for age, gender and total body fat, were observed (all $p \geq 0.13$, table 2 ). Carriers of the minor $T$ allele of SNP rs1944438 had higher total body fat, adjusted for age and gender, compared to homozygous carriers of the $\mathrm{C}$ allele $(\mathrm{p}=0.04)$. 


\section{Longitudinal analyses}

During the 9 months of intervention there were significant mean decreases in body weight (-3.1\%), total body- (-12.1\%), visceral- (-18.7\%) and liver fat (-29.1\%). Over baseline, significantly fewer subjects were still obese (59 subjects, 31.6\%), had IGT (40 subjects, 21.4\%) and fatty liver (39) subjects, $20.9 \%$ ) at follow-up (all $\mathrm{p}<0.0001$ ). Insulin sensitivity estimated from the OGTT increased by $15.5 \%$, and insulin sensitivity measured by the clamp increased by $11 \%$ (table 1 ). Change in insulin sensitivity correlated inversely with changes in total body fat, visceral fat and intramyocellular fat (OGTT: all $\mathrm{p} \leq 0.046$; clamp: all $\leq 0.02$ ). Furthermore, changes in insulin sensitivity correlated inversely with change in liver fat (OGTT: $r=-0.32, p<0.0001$; clamp: $r=-0.32, p=0.03$ ).

The SNP rs 10899116 was not associated with any changes in the parameter tested (all $p \geq 0.38$ ). The SNP rs1944438 was also not associated with changes in total body- (figure, panel A), visceral-, or intramyocellular fat (all $\mathrm{p} \geq 0.39$, table 2). However, subjects carrying the minor $\mathrm{T}$ allele had less decrease in liver fat, independently of age, gender, liver fat at baseline and total body fat at baseline and at follow-up compared to homozygous carriers of the $\mathrm{C}$ allele (table 3 , figure, panel $\mathrm{B}$ ). In contrast, change in adjusted insulin sensitivity calculated from the OGTT was not associated with the SNP (table 3, figure, panel C). Even in the small subgroup of individuals with measurements of insulin sensitivity by the clamp ( $\mathrm{n}=46)$, similar results were found for the relationships of the SNP rs1944438 with changes in liver fat $(\mathrm{p}=0.0021)$ and insulin sensitivity $(\mathrm{p}=0.53)$.

In the group of subjects who had fatty liver at baseline the results were analogous to the larger group. Subjects with fatty liver carrying the minor T allele of SNP rs1944438 had less decrease in adjusted liver fat compared to homozygous carriers of the $\mathrm{C}$ allele $(\mathrm{p}=0.02)$. No relationship was found between the SNP and change in insulin sensitivity calculated from the OGTT $(\mathrm{p}=0.52)$ in these individuals. 
In the smallest group of subjects in our analyses who underwent the clamp $(n=46)$ we had a power of $81 \%$ in the additive model to detect an effect of the DGAT genotype on change in liver fat. The least significant number of subjects to detect the effect at the $\alpha$-level of 0.05 was 30 . In the dominant model the power was $89 \%$ and the least significant number of subjects to detect the effect at the $\alpha$-level of 0.05 was 20. In this group we had a power of $98 \%$ to detect an effect size of $20 \%$ in change of insulin sensitivity at the $\alpha$-level of 0.05 in the dominant model and of $97 \%$ in the additive model, respectively. 


\section{Discussion}

In agreement with animal data $[9 ; 13]$ we found that dissociation between fat accumulation in the liver and insulin resistance mediated by DGAT2 may also exist in humans. During the lifestyle intervention subjects carrying the minor T allele of SNP rs1944438 had less decrease in liver fat compared to homozygous carriers of the $\mathrm{C}$ allele. Importantly, changes in total body-, visceral-and intramyocellular fat did not differ between the genotypes, which is in agreement with a predominant effect of DGAT2 on hepatic steatosis [9]. A recent study, which applied mutation screen in DGAT2, also failed to show an important role of common genetic variation in the gene for the development of obesity[21]. Furthermore, the SNP rs 1944438 of DGAT2 was not associated with change in insulin sensitivity, a finding that is in line with the data in mice [9;13]. Interestingly, the relationships of the SNP with change in liver fat and insulin sensitivity were also observed in the much smaller group of participants who underwent the clamp, supporting that a type 1 error most probably can be excluded.

The dissociation between change in liver fat and insulin sensitivity, which was attributable to the SNP, was apparent in subjects with fatty liver who are at very high risk for metabolic diseases[2;8]. This finding is important particularly since in the treatment of fatty liver moderate lifestyle intervention, as it was used in the present study, is considered the first line therapy [22;23]. It, therefore, underscores the relevance for considering DGAT2 activity during a lifestyle intervention to reduce hepatic steatosis and increase insulin sensitivity. In addition, it remains to be established whether DGAT2 is also important in determining the metabolic effect of pharmacological intervention, e.g. with thiazolidinediones [24], in the treatment of fatty liver.

Mechanisms involved in this dissociation of fatty liver and insulin resistance are not fully understood. As suggested by the animal studies $[9 ; 13 ; 14]$ altered amounts of fatty acid metabolites regulating insulin sensitivity, such as diacylglycerol [25;26], long-chain fatty acyl-CoAs and ceramides [26] may 
be important in this aspect. Furthermore, unsaturated long-chain fatty acyl-CoA were found to have a protective function against saturated acyl-CoAs-induced lipotoxicity and cellular apoptosis by promoting triglyceride accumulation [14;27]. DGAT has the same effect, catalyzing triglyceride synthesis, but whether the SNP rs1944438 of DGAT2 is also associated with such a protective effect in liver in humans, needs to be determined.

In conclusion, our findings support that dissociation between fatty liver and insulin resistance exists in humans. Since during a lifestyle intervention in subjects with fatty liver, the reduction in liver fat does not always result in a beneficial effect on insulin sensitivity, this finding may be of clinical relevance in the prevention and treatment of type 2 diabetes. Genetic screening for this polymorphism prior to the intervention may help to early apply alternative strategies to improve insulin sensitivity. 


\section{Acknowledgements}

The study was supported by a grant from the Deutsche Forschungsgemeinschaft (KFO 114) and the European Community’s FP6 EUGENE6 (LSHM-CT-2004-512013). Dr. Stefan is currently supported by a Heisenberg-Grant of the Deutsche Forschungsgemeinschaft (STE-1096/1-1). 
Table 1 Subject characteristics at baseline and after 9 months of follow-up

\begin{tabular}{|c|c|c|c|}
\hline & Baseline & Follow-up & p value \\
\hline \multicolumn{4}{|c|}{ Demographics and body composition } \\
\hline Gender (males / females) & & 15 & - \\
\hline Age (years) & $48(38-54)$ & $48(39-55)$ & $<0.0001$ \\
\hline Body weight (kg) & $86.5(74.0-96.0)$ & $83.7(71.0-92.5)$ & $<0.0001$ \\
\hline Body mass index $\left(\mathrm{kg} / \mathrm{m}^{2}\right)$ & $28.9(25.8-31.7)$ & $27.8(25.1-31.2)$ & $<0.0001$ \\
\hline Waist circumference $(\mathrm{cm})$ & $97.0(88.0-104.0)$ & $92.0(85.0-101.0)$ & $<0.0001$ \\
\hline Total body fat (kg) & $24.5(17.6-31.8)$ & $21.8(15.9-28.5)$ & $<0.0001$ \\
\hline Visceral fat $(\mathrm{kg})$ & $2.72(1.48-4.14)$ & $2.05(1.14-3.59)$ & $<0.0001$ \\
\hline $\mathrm{IMCL}_{\text {tibialis anterior }}$ (arb.units)* & $3.75(2.81-4.84)$ & $3.43(2.47-4.41)$ & 0.023 \\
\hline Liver fat $(\%)$ & $3.11(1.50-6.90)$ & $2.09(1.02-5.03)$ & $<0.0001$ \\
\hline Fatty liver (liver fat $>5.56 \%$ ) & $28.9 \%(n=54)$ & $20.9 \%(n=39)$ & $<0.0001^{\#}$ \\
\hline \multicolumn{4}{|l|}{ Metabolic characteristics } \\
\hline $\operatorname{ALT}(\mathbf{U} / \mathbf{l})$ & $22(18-30)$ & $21(14-27)$ & 0.0004 \\
\hline AST (U/l) & $22(19-27)$ & $23(19-26)$ & 0.06 \\
\hline$\gamma \mathbf{G T}(\mathbf{U} / \mathbf{l})$ & $18(12-31)$ & $17(11-26)$ & 0.01 \\
\hline Triglycerides (mg/dl) & $102(78-140)$ & $96(69-136)$ & 0.013 \\
\hline Total cholesterol (mg/dl) & $189(166-215)$ & $187(166-210)$ & 0.06 \\
\hline HDL-cholesterol (mg/dl) & $51(43-59)$ & $52(43-60)$ & 0.11 \\
\hline LDL-cholesterol (mg/dl) & 119 (101-139) & $116(95-137)$ & 0.001 \\
\hline Fasting glucose (mM) & $5.17(4.85-5.56)$ & $5.11(4.83-5.44)$ & 0.008 \\
\hline $2 \mathrm{~h}$ glucose $(\mathrm{mM})$ & $6.61(5.72-8.11)$ & $6.33(5.61-7.56)$ & 0.014 \\
\hline NGT / IGT & 138 / 49 & $147 / 40$ & $<0.0001^{\#}$ \\
\hline Fasting insulin (pM) & $50(33-76)$ & $42(30-61)$ & $<0.0001$ \\
\hline $2 \mathrm{~h}$ insulin (pM) & $382(225-594)$ & $303(195-495)$ & $<0.0001$ \\
\hline Insulin sensitivity OGTT(arb. units) & $11.8(7.6-17.3)$ & $13.5(9.1-19.3)$ & $<0.0001$ \\
\hline $\mathrm{ISI}_{\text {Clamp }}\left(\mu \mathrm{mol} \cdot \mathrm{kg}^{-1} \cdot \mathrm{min}^{-1} \cdot \mathrm{pM}^{-1}\right)$ & $0.058(0.042-0.082)^{\S}$ & $0.065(0.047-0.085)^{\S \S}$ & 0.037 \\
\hline
\end{tabular}

Values represent median (interquartile range). For statistical analyses, non-normally distributed parameters were $\log$ transformed. The paired t-test was then applied. ${ }^{\#} \chi^{2}$-test

IMCL, intramyocellular lipids, *available in 175 subjects; NGT, normal glucose tolerance; IGT, impaired glucose tolerance; ISI, insulin sensitivity index, ${ }^{\S}$ available in 142 subjects at baseline and ${ }^{\S} 46$ at follow-up. 
Table 2 Associations of the rs1944438 C/T SNP in DGAT2 with subjects' demographic and metabolic characteriogtics at baseline and follow-up.

\begin{tabular}{|c|c|c|c|c|c|c|c|c|c|c|}
\hline \multirow[b]{3}{*}{ Demographics } & \multicolumn{2}{|c|}{$\mathrm{C} / \mathrm{C}$} & \multicolumn{2}{|c|}{$\mathbf{C} / \mathbf{T}$} & \multicolumn{2}{|c|}{$\mathbf{T} / \mathbf{T}$} & \multicolumn{2}{|c|}{ p baseline } & \multicolumn{2}{|c|}{$\begin{array}{c}p \text { for change } \\
\text { between genotypes }\end{array}$} \\
\hline & \multirow[t]{2}{*}{ Baseline } & \multirow[t]{2}{*}{ Follow-up } & \multirow[t]{2}{*}{ Baseline } & \multirow[t]{2}{*}{ Follow-up } & \multirow[t]{2}{*}{ Baseline } & Follow-畐 & \multicolumn{2}{|c|}{ additive dominant } & \multicolumn{2}{|c|}{ additive dominant } \\
\hline & & & & & & $\div$ & & & & \\
\hline Gender (males / females) & \multicolumn{2}{|c|}{$24 / 43$} & \multicolumn{2}{|c|}{$40 / 54$} & \multicolumn{2}{|c|}{$8 / 18$} & & $0.57^{\#}$ & & \\
\hline Age (years) & $49(41-55)$ & $50(42-56)^{\dagger}$ & $46(36-54)$ & $47(37-55)^{\dagger}$ & $43(39-53)$ & $44(40-5$ \%) & 0.26 & 0.17 & & \\
\hline \multicolumn{11}{|l|}{ Body composition } \\
\hline Body weight $(\mathrm{kg})$ & $83.4(72.5-90.7)$ & $81.2(67.0-88.8)^{\dagger}$ & $88.3(75.0-99.7)$ & $85.5(71.0-97.2)^{\dagger}$ & $89.8(77.3-97.1)$ & $84.6(74.1-8.8)^{*}$ & 0.14 & 0.09 & 0.85 & 0.97 \\
\hline Waist circumference $(\mathrm{cm})$ & $94.0(85.5-102)$ & $89.0(82.5-97.0)^{\dagger}$ & $98.0(88.0-106.0)$ & $96.0(85.0-104)^{\dagger}$ & $97.5(91.5-105)$ & $94.5(83.5-\stackrel{山-402}{\dagger})^{\dagger}$ & 0.09 & 0.052 & 0.051 & 0.03 \\
\hline Total body fat $(\mathrm{kg})$ & $22.6(17.2-26.6)$ & $20.3(14.3-25.6)^{\dagger}$ & $24.9(17.6-31.8)$ & $21.8(16.1-29.7)^{\ddagger}$ & $27.4(20.9-36.3)$ & $25.5\left(19.0-\frac{\overrightarrow{9}}{\widehat{Q}} .3\right)^{+}$ & 0.08 & 0.04 & 0.78 & 0.93 \\
\hline Visceral fat $(\mathrm{kg})$ & $2.46(1.40-3.79)$ & $1.80(1.22-3.23)^{\dagger}$ & $3.01(1.48-4.30)$ & $2.24(1.10-3.82)^{\dagger}$ & $2.91(1.51-4.52)$ & $2.41\left(1.13-\frac{\Phi}{\oplus} 64\right)^{\dagger}$ & 0.94 & 0.91 & 0.41 & 0.63 \\
\hline $\mathrm{IMCL}_{\text {tibialis anterior }}$ (arb.units) * & $3.64(2.54-4.37)$ & $3.64(2.54-4.37)$ & $3.90(2.89-4.89)$ & $3.51(2.49-4.92)$ & $4.28(2.70-5.84)$ & 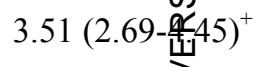 & 0.37 & 0.16 & 0.39 & 0.39 \\
\hline Liver fat (\%) & $2.49(1.41-3.82)$ & $1.62(0.95-3.03)^{\dagger}$ & $3.96(1.63-9.32)$ & $2.68(1.14-6.01)^{\dagger}$ & $3.12(1.13-5.69)$ & $2.09(0.91$ 余 43$)$ & 0.07 & 0.18 & 0.023 & 0.008 \\
\hline \multicolumn{11}{|l|}{ Metabolic characteristics } \\
\hline Fasting glucose $(\mathrm{mM})$ & $5.22(4.83-5.53)$ & $5.17(4.83-5.53)$ & $5.17(4.88-5.68)$ & $5.11(4.83-5.44)^{\ddagger}$ & $5.10(4.82-5.42)$ & $5.09\left(4.78-\frac{Q}{Z} 40\right)$ & 0.22 & 0.77 & 0.33 & 0.14 \\
\hline $2 \mathrm{~h}$ glucose $(\mathrm{mM})$ & $6.61(5.94-7.72)$ & $6.44(5.61-7.67)$ & $6.67(5.82-8.17)$ & $6.17(5.49-7.43)^{\ddagger}$ & $6.31(5.24-7.56)$ & $6.45(5.57$-P.P. 76$)$ & 0.12 & 0.77 & 0.65 & 0.65 \\
\hline Fasting insulin (pM) & $39(31-73)$ & $40(29-69)^{+}$ & $58(36-79)$ & $43(32-60)^{\dagger}$ & $39(32-80)$ & 42 (30-麗) & 0.19 & 0.59 & 0.73 & 0.45 \\
\hline $2 \mathrm{~h}$ insulin (pM) & $310(205-519)$ & $281(165-433)^{*}$ & $456(260-683)$ & $312(197-502)^{\dagger}$ & $267(158-564)$ & $401(194-536)$ & 0.006 & 0.35 & 0.16 & 0.38 \\
\hline Insulin sensitivity оGтT (AU) & $14.2(8.4-19.2)$ & $14.3(9.2-21.4)^{+}$ & $9.6(6.9-13.6)$ & $13.1(8.9-18.0)^{\dagger}$ & $15.3(8.1-20.9)$ & $14.2(9.2-21.0)$ & 0.003 & 0.13 & 0.93 & 0.76 \\
\hline ISI $_{\text {Clamp }}\left(\mu \mathrm{mol} \cdot \mathrm{kg}^{-1} \cdot \mathrm{min}^{-1} \cdot \mathrm{pM}^{-1}\right)^{\S}$ & $.071(.051-.097)$ & $.073(.057-.115)$ & $.053(.039-.068)$ & $.050(.038-.076)$ & $.059(.044-.088)$ & $.082(.068-.110)$ & 0.051 & 0.17 & 0.26 & 0.53 \\
\hline
\end{tabular}

Values represent median (interquartile range). For statistical analyses, non-normally distributed parameters were log transformed. ${ }^{+} \mathrm{p}<0.05,{ }^{\dagger} \mathrm{p}<0.01$ and ${ }^{\dagger} p<0.001$ for paired differences between baseline and follow-up. ${ }^{\#} \chi^{2}$-test. The genotype effect at baseline and during the intervention was tested using an additive and a dominant model. Body weight, waist circumference and total body fat at baseline were adjusted for age and gender. The other parameters were additionally adjusted for total body fat. Change in body weight, waist circumference and total body fat were adjusted for the respective baseline values, gender and age at follow-up. Changes in the other parameters were additionally adjusted for body fat at baseline and follow-up. IMCL, intramyocellular lipids, *available in 149 subjects; ISI, insulin sensitivity index, ${ }^{\S}$ available in 142 subjects $(\mathrm{C} / \mathrm{C} \mathrm{n}=55$; C/T $\mathrm{n}=67, \mathrm{~T} / \mathrm{T} \mathrm{n}=20)$ at baseline and $46(\mathrm{C} / \mathrm{C} \mathrm{n}=16 ; \mathrm{C} / \mathrm{T} \mathrm{n}=24, \mathrm{~T} / \mathrm{T} \mathrm{n}=6)$ at follow-up. 
Table 3 Determinants of change in liver fat and insulin sensitivity calculated from the (OGTT) in multivariate regression models

\begin{tabular}{|c|c|c|}
\hline Covariates & F Ratio & $\mathbf{p}$ \\
\hline \multicolumn{3}{|l|}{ Change in liver fat (additive model) } \\
\hline Liver fat at baseline & 31.66 & 0.0001 \\
\hline Female sex & 0.009 & \\
\hline Age at follow-up & 0.015 & 0.90 \\
\hline Total body fat at baseline & 0.086 & 0.77 \\
\hline Total body fat at follow-up & 5.170 & 0.024 \\
\hline DGAT2 rs 1944438 & 3.863 & 0.023 \\
\hline \multicolumn{3}{|c|}{ Change in liver fat (dominant model) } \\
\hline Liver fat at baseline & 33.46 & $<0.0001$ \\
\hline Female sex & 0.009 & 0.92 \\
\hline Age at follow-up & 0.030 & 0.86 \\
\hline Total body fat at baseline & 0.067 & 0.80 \\
\hline Total body fat at follow-up & 5.326 & 0.022 \\
\hline DGAT2 rs 1944438 & 7.210 & 0.008 \\
\hline \multicolumn{3}{|c|}{ Change in insulin sensitivity (additive model) } \\
\hline Insulin sensitivity at baseline & 42.86 & $<0.0001$ \\
\hline Female sex & 0.770 & 0.38 \\
\hline Age at follow-up & 0.677 & 0.41 \\
\hline Total body fat at baseline & 0.802 & 0.37 \\
\hline Total body fat at follow-up & 16.62 & $<0.0001$ \\
\hline DGAT2 rs 1944438 & 0.068 & 0.93 \\
\hline \multicolumn{3}{|c|}{ Change in insulin sensitivity (dominant model) } \\
\hline Insulin sensitivity at baseline & 44.61 & $<0.0001$ \\
\hline Female sex & 0.774 & 0.38 \\
\hline Age at follow-up & 0.702 & 0.40 \\
\hline Total body fat at baseline & 0.845 & 0.36 \\
\hline Total body fat at follow-up & 16.67 & $<0.0001$ \\
\hline DGAT2 rs 1944438 & 0.090 & 0.76 \\
\hline
\end{tabular}




\section{Figure legend}

Percentage of change (follow-up over baseline) in total body fat (A), liver fat (B) and insulin sensitivity estimated from the OGTT (C) during the 9 months of follow-up in relation to the genotype of the rs1944438 C/T polymorphism in DGAT2. Change in total body fat was adjusted for total body fat at baseline, gender and age at follow-up. Changes in the other parameters were adjusted for the respective parameters at baseline, gender, age at follow-up, and body fat at baseline and at follow-up. In the regression model non-normally distributed parameters were logarithmically transformed. Statistical significance is depicted using an additive as well as a dominant model. 


\section{References}

1. Loria,P., Lonardo,A., Targher,G. (2008) Is liver fat detrimental to vessels?: intersections in the pathogenesis of NAFLD and atherosclerosis. Clin Sci (Lond.) 115, 1-12.

2. Roden,M. (2006) Mechanisms of Disease: hepatic steatosis in type 2 diabetes--pathogenesis and clinical relevance. Nat.Clin.Pract.Endocrinol.Metab 2, 335-348.

3. Targher,G., Bertolini,L., Padovani,R. et al. (2007) Prevalence of nonalcoholic fatty liver disease and its association with cardiovascular disease among type 2 diabetic patients. Diabetes Care 30, 1212-1218.

4. Targher,G. and Arcaro,G. (2007) Non-alcoholic fatty liver disease and increased risk of cardiovascular disease. Atherosclerosis 191, 235-240.

5. Shibata,M., Kihara,Y., Taguchi,M., Tashiro,M. and Otsuki,M. (2007) Nonalcoholic fatty liver disease is a risk factor for type 2 diabetes in middle-aged Japanese men. Diabetes Care 30, 29402944.

6. Kelley,D.E., McKolanis,T.M., Hegazi,R.A., Kuller,L.H. and Kalhan,S.C. (2003) Fatty liver in type 2 diabetes mellitus: relation to regional adiposity, fatty acids, and insulin resistance. Am.J.Physiol Endocrinol.Metab 285, E906-E916.

7. Utzschneider,K.M. and Kahn,S.E. (2006) Review: The role of insulin resistance in nonalcoholic fatty liver disease. J.Clin.Endocrinol.Metab 91, 4753-4761.

8. Kotronen,A. and Yki-Jarvinen,H. (2008) Fatty liver: a novel component of the metabolic syndrome. Arterioscler.Thromb.Vasc.Biol. 28, 27-38.

9. Monetti,M., Levin,M.C., Watt,M.J. et al. (2007) Dissociation of hepatic steatosis and insulin resistance in mice overexpressing DGAT in the liver. Cell Metab 6, 69-78.

10. Stefan,N., Kantartzis,K. and Haring,H.U. (2008) Causes and Metabolic Consequences of Fatty Liver. Endocr Rev, 2008 Aug 21. [Epub ahead of print]

11. Stone,S.J., Myers,H.M., Watkins,S.M. et al. (2004) Lipopenia and skin barrier abnormalities in DGAT2-deficient mice. J.Biol.Chem. 279, 11767-11776.

12. Yu,Y.H. and Ginsberg,H.N. (2004) The role of acyl-CoA:diacylglycerol acyltransferase (DGAT) in energy metabolism. Ann.Med. 36, 252-261.

13. Yu,X.X., Murray,S.F., Pandey,S.K. et al. (2005) Antisense oligonucleotide reduction of DGAT2 expression improves hepatic steatosis and hyperlipidemia in obese mice. Hepatology 42, 362-371. 
14. Choi,C.S., Savage,D.B., Kulkarni,A. et al. (2007) Suppression of diacylglycerol acyltransferase-2 (DGAT2), but not DGAT1, with antisense oligonucleotides reverses diet-induced hepatic steatosis and insulin resistance. J.Biol.Chem. 282, 22678-22688.

15. Stefan,N., Hennige,A.M., Staiger,H. et al. (2006) Alpha2-Heremans-Schmid glycoprotein/fetuin$\mathrm{A}$ is associated with insulin resistance and fat accumulation in the liver in humans. Diabetes Care 29, 853-857.

16. Stefan,N., Hennige,A.M., Staiger,H. et al. (2007) High circulating retinol-binding protein 4 is associated with elevated liver fat but not with total, subcutaneous, visceral, or intramyocellular fat in humans. Diabetes Care 30, 1173-1178.

17. Stefan,N., Machicao,F., Staiger,H. et al. (2005) Polymorphisms in the gene encoding adiponectin receptor 1 are associated with insulin resistance and high liver fat. Diabetologia 48, 2282-2291.

18. Report of the Expert Committee on the Diagnosis and Classification of Diabetes Mellitus (1997) Diabetes Care 20, 1183-1197.

19. Matsuda,M. and DeFronzo,R.A. (1999) Insulin sensitivity indices obtained from oral glucose tolerance testing: comparison with the euglycemic insulin clamp. Diabetes Care 22, 1462-1470.

20. Szczepaniak,L.S., Nurenberg,P., Leonard,D. et al. (2005) Magnetic resonance spectroscopy to measure hepatic triglyceride content: prevalence of hepatic steatosis in the general population. Am.J.Physiol Endocrinol.Metab 288, E462-E468.

21. Friedel,S., Reichwald,K., Scherag,A. et al. (2007) Mutation screen and association studies in the diacylglycerol O-acyltransferase homolog 2 gene (DGAT2), a positional candidate gene for early onset obesity on chromosome 11q13. BMC.Genet. 8, 17.

22. Harrison,S.A. and Day,C.P. (2007) Benefits of lifestyle modification in NAFLD. Gut 56, 17601769.

23. Tilg,H. and Kaser,A. (2005) Treatment strategies in nonalcoholic fatty liver disease. Nat.Clin.Pract.Gastroenterol.Hepatol. 2, 148-155.

24. Belfort,R., Harrison,S.A., Brown,K. et al. (2006) A placebo-controlled trial of pioglitazone in subjects with nonalcoholic steatohepatitis. N.Engl.J.Med. 355, 2297-2307.

25. Samuel,V.T., Liu,Z.X., Wang,A. et al. (2007) Inhibition of protein kinase Cepsilon prevents hepatic insulin resistance in nonalcoholic fatty liver disease. J.Clin.Invest 117, 739-745.

26. Kim,J.K., Fillmore,J.J., Chen,Y. et al. (2001) Tissue-specific overexpression of lipoprotein lipase causes tissue-specific insulin resistance. Proc.Natl.Acad.Sci.U.S.A 98, 7522-7527.

27. Listenberger,L.L., Han,X., Lewis,S.E. et al. (2003) Triglyceride accumulation protects against fatty acid-induced lipotoxicity. Proc.Natl.Acad.Sci.U.S.A 100, 3077-3082. 
A

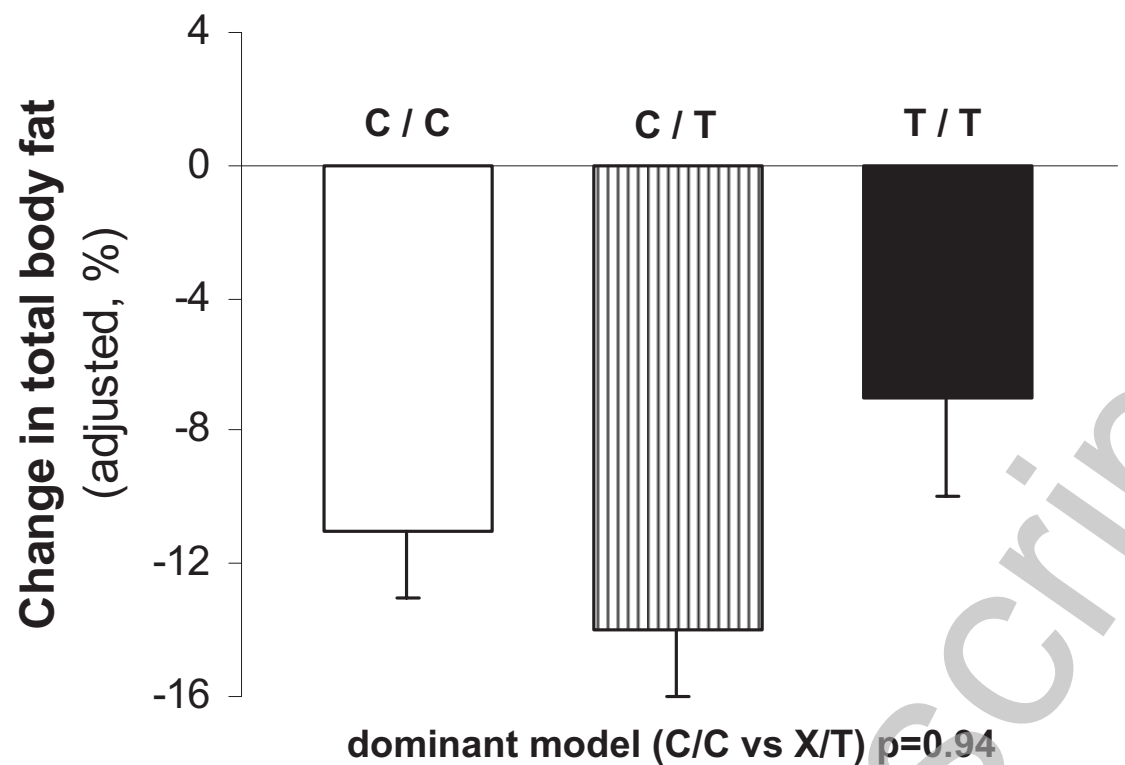

additive model $p=0.78$

B

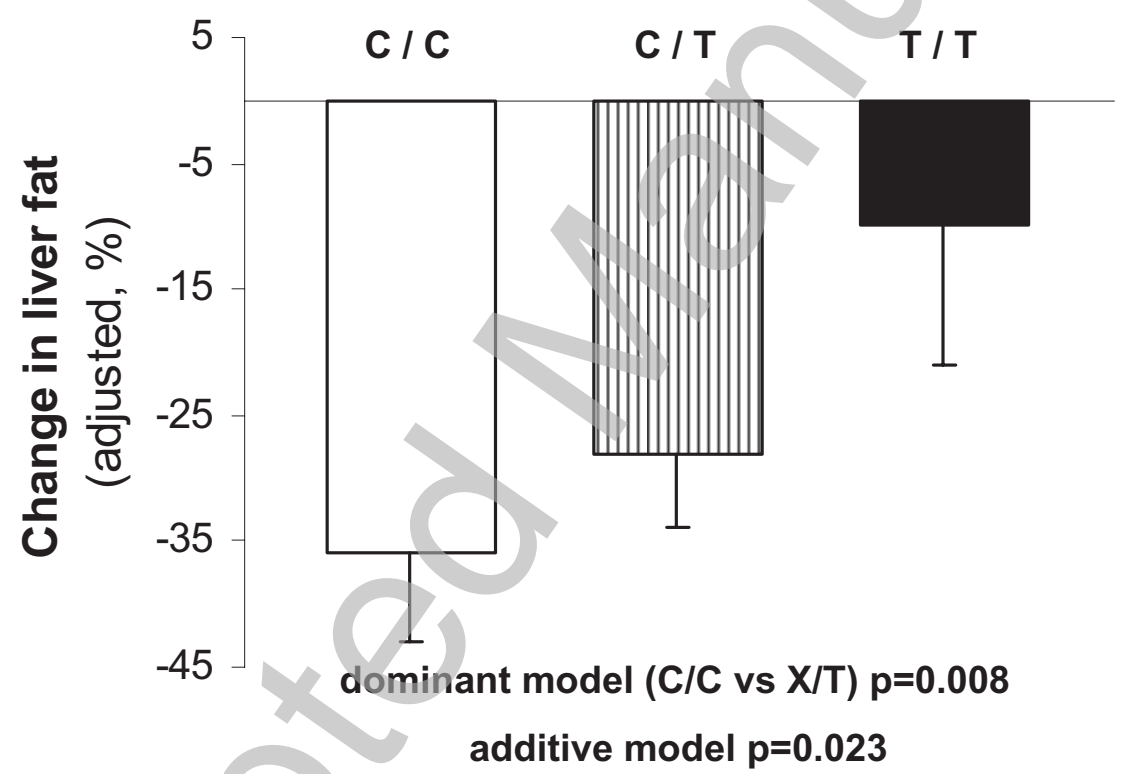

C

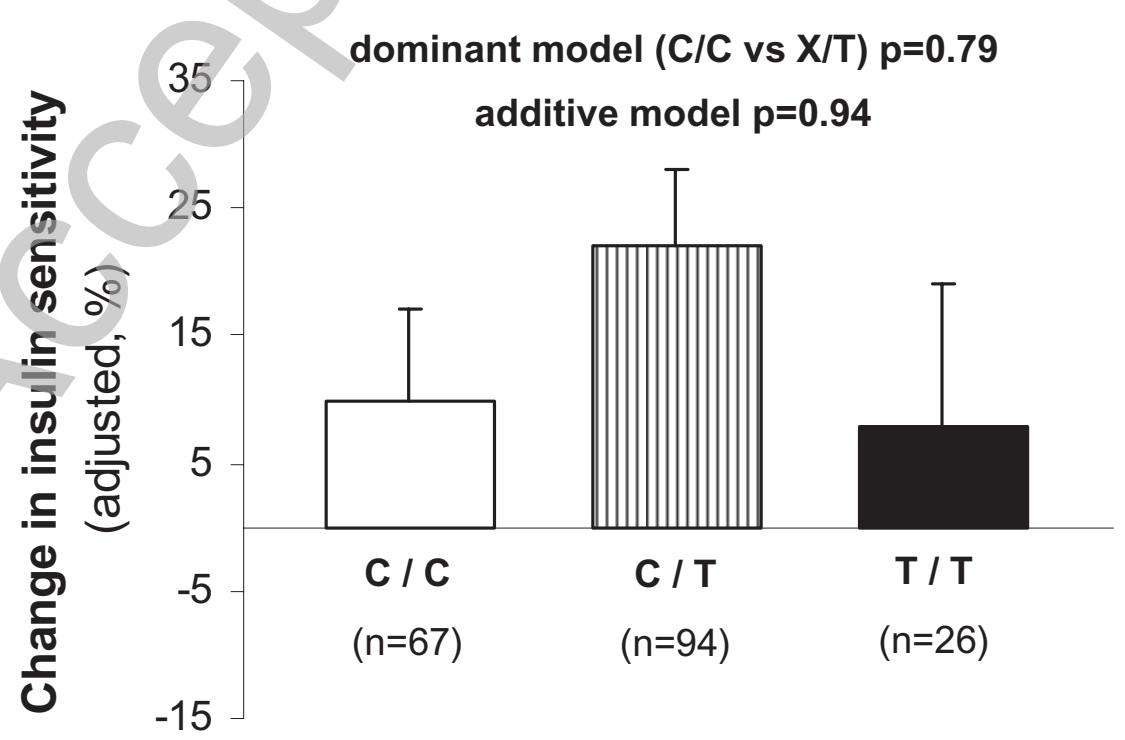

